\title{
Mujeres fatales desafían el statu quo. Estudio de tres novelas del mundo hispánico y su adaptación cinematográfica
}

\section{Femme Fatales Defying Status Quo. A Study of Three Hispanic Novels and their Film Adaptation}

Verónica Hernández Landa Valencia Universidad Nacional Autónoma de México verohernandez12@gmail.com

Resumen: La mujer fatal ha sido estudiada como un recurso del que se valió el arte para estigmatizar y someter a las mujeres que, a lo largo de la historia, se rebelaron contra el statu quo. Sin embargo, también a través de ella se han señalado las debilidades, hipocresías, decadencia y autoritarismos del orden patriarcal en el que se inserta. El presente artículo tiene como objetivo explorar esa ambivalente funcionalidad del personaje, por medio del contraste entre tres discursos novelescos en los que la mujer fatal se constituye en eje problemático de la trama, y las diferentes propuestas de resignificación del mismo que resultaron de las adaptaciones cinematográficas. Se trata de novelas hispánicas publicadas en el último tercio del siglo xx, Pantaleón y las visitadoras, de Mario Vargas Llosa, Luna caliente, de Mempo Giardinelli, y Las edades de Lulú, de Almudena Grandes, y de las respectivas adaptaciones dirigidas por Francisco Lombardi, Roberto Denis y Bigas Luna. La comparación toma como unidad de análisis el tópico de la poderosa sexualidad que conduce a la perdición; para alcanzar el objetivo del estudio se propone una con- 
ceptualización del tópico que permite visibilizar su función retórica y su capacidad de adaptarse y resignificarse en cada nuevo discurso. Con esta propuesta se busca no solo resaltar la ambivalencia y el potencial transgresor de la mujer fatal, sino también promover el enfoque retórico en el análisis de los tópicos y de los personajes tematizados por la tradición literaria.

Palabras clave: femme fatale, retórica, novela, cine, tópicos.

Abstract: The femme fatale has been studied as a figure in art used by men artists to stigmatize and subjugate all women who rebelled against the statu quo throughout history. However, femme fatale has also been used to point out the weaknesses, hypocrisies, decadence and authoritarianism of the patriarchal system where it is set. This paper aims to explore the character's ambivalent function, by contrasting three novels in which the femme fatale becomes the axis of conflict in the plot, and the proposals to resignify its meaning by film adaptations. These are Hispanic novels published in the last third of the twentieth century: Captain Pantoja and the Special Service, by Mario Vargas Llosa, Sultry Moon, by Mempo Giardinelli, and The Ages of Lulu, by Almudena Grandes; and their respective adaptations directed by Francisco Lombardi, Roberto Denis and Bigas Luna. This comparison focuses in the analysis of the topos of a powerful sexuality that leads to ruin. In order to study this figure, the paper proposes a conceptualization of the topos that allows to visualize its rhetorical function and its capability to adapt and resignify itself in every discourse. This proposal seeks not only to highlight the ambivalence and transgressive potential of the femme fatale, but also to promote the rhetorical analysis in the study of topo $i$ and thematized characters in literary tradition.

Keywords: Femme fatale, Rhetoric, Novel, Cinema, Topoi. 
Recibido: 23 de marzo de 2020

Aceptado: 4 de septiembre de 2020 https://dx.doi.org/I O. I 5 I 74/rv.vI 3i27.539

T a mujer fatal ha sido estudiada frecuentemente como arquetiLpo, desde enfoques antropológicos que señalan que el personaje reitera significaciones primigenias según las cuales la mujer conduce a la perdición del hombre. Para Erika Bornay, Tomás Moreno y Golrokh Eetessam, la literatura se ha valido del arquetipo para estigmatizar y someter a las mujeres rebeldes al orden patriarcal. Ellos hacen un recorrido por las imágenes, motivos, símbolos o tópicos que han consolidado el arquetipo, desde Lilith, pasando por las brujas medievales, hasta la bella dama sin piedad, de John Keats, para luego estudiar su influencia en un personaje propio de la segunda mitad del siglo xix: la femme fatale. Todos coinciden en que su representación artística fue un medio para estigmatizar y someter a la mujer en una época en que se independizaba del varón y luchaba por sus derechos civiles.

Desde ese enfoque, el arte prerrafaelista, simbolista y decadentista resultarían conservadores y machistas en su visión de la mujer. Sin embargo, ocasionalmente se reconoce que la tendencia finisecular a representar a la mujer fatal en todo su poder seductor conllevaba cierto carácter transgresor: "el hombre no puede evitar quedar fascinado por ella, aun poniendo en peligro los fundamentos de su dominación” (Moreno, 2015: 228). Y, es que, para entender en su complejidad al personaje del siglo xIx, hace falta relacionarlo con valores surgidos en la modernidad.

Pasados el romanticismo y el simbolismo, la mujer fatal no podía mantenerse ajena a la idealización y reivindicación de la belleza y rebeldía de la que fueron objeto distintos personajes de la cultura, como Lucifer y Prometeo. Aunque se les llegara a condenar a un desenlace trágico en poemas y relatos, su sola transgresión, 
al presentarse tan atractiva, deseable y poderosa, y tan moderna, implicaba un cuestionamiento al statu quo, que, al lado de estos personajes, resultaba opresivo y decadente.

Según los estudiosos de la mujer fatal, esta se fue desdibujando en la pintura y la literatura del siglo $\mathrm{xx}$, y si bien trascendió al cine, entró en franca decadencia, al ser objeto de caricaturización y parodia hollywoodense. No obstante, para Javier Meléndez la representación tuvo consecuencias contrarias: "la meca del cine se pegó un tiro en el pie: al demonizar la inteligencia de las mujeres, la puso de relieve" (Meléndez, 2018).

En este artículo me propongo ahondar en el desarrollo de la mujer fatal en la novela y el cine del siglo xx con el fin de destacar el potencial transgresor que adquiere en cada discurso. Para ello me distancio del concepto de arquetipo, optando por el de personaje tematizado, que se construye a partir de tópicos. Específicamente, analizo el tópico de la sexualidad poderosa que ejerce dominio sobre el entorno -y en especial sobre los hombres-, para mostrar que la mujer fatal ha sido representada con distintos fines comunicativos, incluido el cuestionamiento del statu quo, aunque también, en algunos casos, su reafirmación. Analizo un corpus hispano, porque en estas latitudes hay una tradición de mujeres fatales que no ha recibido la atención que merece entre las teorías sobre la mujer fatal.

Las novelas son: Pantaleón y las visitadoras (1973), del peruano Mario Vargas Llosa, Luna caliente (1983), del argentino Mempo Giardinelli, y Las edades de Lulú (1989), de la española Almudena Grandes. Cada una de ellas presenta un manejo retórico distinto del tópico; pero lo que hará aún más patente que el tópico cambia sus significaciones en cada discurso será el análisis de las adaptaciones cinematográficas: las de Francisco Lombardi (1999), Roberto 
Denis (1985) y Bigas Luna (1990), respectivamente. ${ }^{1}$ Personaje, tópico y trama, a pesar de compartir rasgos esenciales, pueden cambiar radicalmente sus significaciones y su potencial retórico al integrarse a discursos y lenguajes distintos.

Antes de proceder al análisis, son necesarias ciertas precisiones porque la noción de tópico que aquí se emplea no es la misma de la tematología actual, o la de Ernst Robert Curtius en su multicitado trabajo Literatura europea y Edad Media latina, sino una más cercana a la retórica clásica. Desde este enfoque, analizaré al tópico como un elemento constitutivo del personaje tematizado de la ferme fatale.

\section{Tópico y personaje}

El concepto actual de tópico tiene como referente básico el trabajo de Curtius, quien señala que son "argumentos para los casos más variados; [...] temas ideológicos a propósito para cualquier desa-

${ }^{1}$ La primera adaptación de Pantaleón y las visitadoras fue en 1976, bajo la dirección de José María Gutiérrez, con estrecha colaboración de Vargas Llosa; opté por analizar la de 1999 porque tuvo mejor y mayor recepción, especialmente en la patria de Vargas Llosa (Esteban Hernández, s.f.) y el escritor no participó directamente en la producción. En cuanto a Luna caliente, aunque la versión de Denis no tuvo mucho éxito ni está particularmente bien lograda, la preferí a la de Vicente Aranda de 2009 -que también pasó desapercibida por la crítica-, porque esta última implicó una recontextualización de la diégesis al ámbito peninsular y generaba variables culturales que no influían significativamente en los resultados de mi estudio, pero sí hacían más complejo el análisis. Solo hay una adaptación de la novela de Grandes; ella colaboró con Bigas Luna, pero no quedó satisfecha con el tinte moral de la película (Sanabria, 2018: 49). Evidentemente la elección de las adaptaciones puede ser cuestionable, y el estudio se podría ampliar a todas las adaptaciones existentes, pero la selección que hice es funcional para el propósito de un primer acercamiento al fenómeno que aquí interesa: la construcción de la mujer fatal en la narrativa hispánica y las transformaciones que supone su adaptación al cine. 
rrollo o variación” (Curtius, 1995: 108), y que en el ámbito literario terminaron funcionando como "clichés literarios aplicables a todos los casos" (109). Se puede advertir en esta definición un paulatino deslizamiento: primero se perfila la función argumentativa que le atribuyó la retórica clásica; posteriormente, su papel temático; finalmente, cierto carácter formulario, acotado a la literatura. ${ }^{2}$

Entre los tópicos se consideran elementos muy disímiles: descriptio puellae, locus amoenus, carpe diem, fotitudo et sapientia, alabanza de los antepasados, falsa modestia. Algunos son descriptivos, otros enuncian actitudes y valores, y, otros más, expresiones formulísticas. Lo que comparten entre sí es que se repiten en la tradición, pueden variar en la forma y el significado, pero dentro de esas variaciones siempre se reconoce cierta identidad formal y semántica. En cuanto a su función ideológica, dado que el tópico es visto como cliché, generalmente se asume que reitera y reafirma significaciones tradicionales. ${ }^{3}$

${ }^{2}$ La tematología tiende a estudiar el tópico en relación con el motivo, sin embargo, en la distinción entre ambos conceptos se observan variaciones notables. Los planteamientos más cercanos a Curtius definen al tópico como una unidad de carácter transtextual, materia abstracta reconocida por un círculo de cultura, que puede agrupar o coincidir con alguno de los motivos constitutivos de obra literaria en particular (Márquez, 2002: 251-256); para otros, es una unidad recurrente a lo largo de la historia literaria, de carácter estereotipado, que se compone de motivos (Cabello Pino, 2010: 25); algunos más recuperan la división de Tomashevski entre motivos indivisibles e históricamente indivisos para plantear que los tópicos pertenecen a estos últimos: "su expresión puede ser dúctil $[\ldots]$ pero en conjunto sí transmigran como entidad unitaria” (López Martínez, 2008: 21-22). Por su parte, Pimentel, considera que los tópicos son un tipo de motivo que se caracteriza por su bajo grado de abstracción, como "cristalización verbal de una idea", que contrastaría con motivos más abstractos, cuya expresión formal o verbal es más indefinida, como la idea de la rebelión (Pimentel, 1993: 220).

${ }^{3}$ Desde un planteamiento semiótico, Ramón Pérez Parejo (2004: 62) sí considera la dimensión ideológica de los tópicos, al afirmar que "son testimonio de una 
Para considerar la potencial resignificación del tópico, y sus implicaciones ideológicas, resulta particularmente útil retomar la concepción clásica. Más que tratarse de frases hechas o conceptos automatizados, para los rétores de la antigüedad los lugares comunes funcionaban como esquemas o lugares de donde se extraían los argumentos, ${ }^{4}$ pero no como argumentos en sí. Según Aristóteles, existen los lugares de la semejanza y la desemejanza, de lo posible y lo imposible, de las relaciones recíprocas, los contrarios, la amplificación y la disminución, etcétera, y cada uno de ellos implica una forma distinta de relacionar premisas para generar un argumento.

Así, por ejemplo, las relaciones recíprocas consisten en que "si es pertinente a uno de los dos términos obrar bella y justamente, lo será al otro recibirlo así; y si al uno mandar, al otro cumplir" (1397a: 24-25). Este tópico implica establecer relaciones de reciprocidad entre términos opuestos o correlativos para hacer verosímil un argumento, y se puede aplicar a los casos más diversos: a un beneficio corresponde la gratitud; si uno gobierna, otros son gobernados; el fuerte existe porque hay débiles. De este modo, si se afirma que las mujeres son poderosas, al apoyarnos en el lugar de las relaciones recíprocas, resulta verosímil afirmar que ello implica debilidad en los hombres.

El argumento derivado del tópico, por sí mismo y fuera de contexto, no tiene ninguna connotación moral o ideológica con res-

actitud espiritual y también de una forma de entender el mundo y de crear un modelo de mundo literario determinado. [...] los tópicos son como son por la sociedad en que fueron creados y, por tanto, responden a un modelo de mundo del que son productos dignos de atención al estar cristalizados", pero asegura que están altamente automatizados, de modo que no tienen poder creativo, sino que sirven al statu quo.

${ }^{4}$ Existen ciertas diferencias entre las definiciones de Aristóteles y Quintiliano con respecto a los tópicos, pero no son relevantes para los propósitos de esta investigación. Cabe resaltar que Quintiliano rechaza explícitamente la identificación de tópico con tema (Quintiliano, 1997: Libr. V, cap. X, pte. II). 
pecto a los hombres o las mujeres; expresa una forma de conceptualizar a la sociedad que presupone un orden jerárquico y recíproco. En este sentido, el argumento puede emplearse para defender causas opuestas. Solo cuando se insertan en discursos concretos, situados en circunstancias comunicativas que presuponen ciertos valores sociales, los argumentos adquieren connotaciones ideológicas perfectamente identificables, pero no necesariamente conciliables con las que adquirirán al ser usados en otra enunciación. En un discurso dirigido a una sociedad patriarcal que tiende a conservar el orden y los valores tradicionales, si se afirma que "el poder de la mujer debilita al hombre", el auditorio inferirá la necesidad de contrarrestar el poder que haya adquirido la mujer. Si la misma frase se inserta en una denuncia de la decadencia del sistema patriarcal, se entendería como un llamado al empoderamiento de la mujer, o incluso al trastocamiento de las relaciones de poder.

Algunos de los argumentos derivados de la tópica, por su eficacia persuasiva, terminan por repetirse en distintos discursos a lo largo del tiempo. A esos argumentos manidos también se les ha dado el nombre de tópicos. De este modo, se puede afirmar que la idea de que el poder de la mujer debilita al hombre se ha repetido tanto, a lo largo de la historia y en diferentes tipos de discursos, que se convirtió en un cliché.

Con la paulatina restricción de la retórica al campo literario, los tópicos fueron reducidos a una función temática, bajo una creciente convicción de que la literatura no era argumentativa. Sin embargo, en las últimas décadas distintos estudiosos, como Wayne C. Booth y Antonio García Berrio, realzan el papel de la argumentación en los textos literarios, que procuran persuadir sobre la validez o verosimilitud de una visión de mundo. Desde esta perspectiva emplearé el tópico para analizar a la mujer fatal.

Parto de un argumento ya formalizado, el de la poderosa sexualidad que permite a la mujer ejercer dominio sobre el hombre 
y su entorno, tomando en cuenta que a él subyace el lugar de las relaciones recíprocas. Esta forma de argumentación se hará presente en la estructura general de los discursos en que se inserta el personaje de la fermme fatale, en los cuales se desarrolla, entre otros temas, el problema de las relaciones de poder.

En cuanto a la ferme fatale, retomo el concepto de tema-personaje, con que Luz Aurora Pimentel se refiere a Fausto o a Salomé:

Estos temas-personaje se construyen a partir de un texto original, un mito o una leyenda que luego se toma como materia prima para un nuevo texto. La tradición literaria al cristalizarlos los convierte en una especie de esquemas de orden pre-textual. No obstante, la cristalización de la historia, mito o leyenda no implica necesariamente una significación fija o predeterminada para todas sus realizaciones; por el contrario, el tema-especialmente el temapersonaje- se nos presenta como un esquema ideológicamente vacío, susceptible de proyectar los más diversos contenidos. Ahora bien, debido a que los temas-personaje [...] tienen un grado más alto de prefiguración [...] una especie de "perfil narrativo" que les da su identidad como tal, es imposible "vaciarlos" totalmente de los contenidos ideológicos que marcan las versiones anteriores. De tal manera que en los temas-personaje se observa la tensión entre los nuevos investimentos de orden semántico e ideológico a los que se somete un tema personaje y la "memoria intertextual" de los anteriores (Pimentel, 1993: 218).

La mujer fatal se entenderá entonces como un tipo de personaje surgido a partir de otros (Lilith, Cleopatra, Elena de Troya, etc.) que fueron identificados por características semejantes, y que se cristalizó en la tradición literaria hasta formar ese esquema de orden pretextual. Este tema-personaje, para ser reconocible en cual- 
quier relato, debe cubrir cierto "perfil narrativo": ${ }^{5}$ independencia, iniciativa y frialdad calculadora, provocar o ser causa de alguna fatalidad. Este perfil incluye tópicos, como la sexualidad poderosa.

En conformidad con el concepto de tópico desarrollado previamente, este tema-personaje, aunque no está vacío de contenidos ideológicos tradicionales, tampoco está absolutamente determinado; las significaciones previas pueden entrar en tensión con otras originales en cada nuevo discurso.

\section{Las visitadoras de Pantilandia}

La novela de Vargas Llosa inicia con un epígrafe, tomado de $L a$ educación sentimental de Flaubert, que marca ciertas pautas de interpretación: "Il y a des hommes n'ayant pour mission parmi les autres que de servir d'intermédiaires; on les franchit comme des ponts, et l'on va plus loin" (Flaubert apud. Vargas Llosa, 2010: 9). ${ }^{6}$ El recién ascendido a capitán, Pantaleón Pantoja, debe organizar un servicio de prostitutas (a quienes da el eufemístico nombre de visitadoras) para que atienda a los números del ejército peruano afincados en la región del Amazonas, y así estos dejen de violar a las pobladoras de Iquitos. Mientras la misión fue exitosa y discreta, benefició a pobladores, militares, prostitutas, periodistas y altos mandos; pero una vez que surgieron los problemas, Pantaleón fue

${ }^{5}$ Como señalo en una nota previa, Pimentel considera el tópico como un tipo de motivo, pero la distinción entre tópico y motivo conduce a problemas conceptuales ajenos al enfoque retórico que aquí se le ha dado al topos; en cambio, el concepto de tema-personaje permite visualizar una categoría que funciona como centro de imantación de una serie de elementos, incluidos los tópicos, y que se caracteriza por su memoria intertextual, pero también por la posibilidad de llenarse de nuevas significaciones en cada discurso.

6 "Hay hombres que solo tienen por misión entre los demás la de servir de intermediarios; se pasa por ellos como sobre puentes y se va más lejos" (Flaubert, 1891: 74-75). 
el puente sobre el que pasaron todos los demás. El militar intachable y con aspiraciones de ascenso se sumergió en un pantano de corruptelas, vicios, envidias, ambiciones, fanatismos religiosos y dramas familiares, y en su intento de poner orden salió salpicado y degradado. La novela, configurada como un concierto de voces que se entretejen con la de Pantoja, muestra cómo la identidad de este último se fue contagiando de la otredad.

Desde este ángulo surge la impresión de que Pantaleón es una víctima, entre otras cosas, de la mujer y del poder sexual. Sin embargo, la manufactura paródica apunta a desestabilizar cualquier significación convencional, incluido el orden que representa Pantoja. De acuerdo con Cánovas, en esta obra "el Ejército es un bulín; su cuerpo de generales, los regentes o cabrones; los capitanes, unos cafiches; la tropa, un cuerpo putañero y las princesas o prostitutas, el cuerpo de élite" (Cánovas, 2003: 43) y Pantilandia, el centro de operaciones de las visitadoras, es la caricatura del vano esfuerzo masculino por domesticar y civilizar la sexualidad (50-51). Es en este último aspecto en el que me centraré a continuación.

Las prostitutas son un elemento central del mundo carnavalizado; con su sexualidad poderosa, abierta y libre, exhiben las debilidades, envidias e hipocresías de los otros, como el sacerdote del ejército, censor del cuerpo de visitadoras y al mismo tiempo cliente de prostitutas. Estas no están exentas de mezquindades, ambiciones o hipocresías, pero, a diferencia de otros, no pretenden erigirse en autoridad moral. Una vez que adquieren un papel protagónico, la imagen del hombre civilizador (militar, sacerdote o periodista) se debilita hasta mostrar sus dobleces.

Pantaleón es el ideal de la disciplina militar, racionalista y patriarcal, "un oficial sin vicios" (Vargas Llosa, 2010: 13), "organizador nato, sentido matemático del orden, capacidad ejecutiva” (14); la selva y las prostitutas son el poder indómito de la naturaleza que amenaza con destruirlo. Mientras él intenta ordenar el ejercicio de 
la sexualidad con reglas, horarios y disciplina que informa meticulosamente a sus superiores, ellas "exhiben agresivamente su condición mujeril, yerguen el busto, quiebran las cinturas, tiemblan las nalgas y sacuden las largas cabelleras" (Vargas Llosa, 2010: 56), y dan al a su lugar de trabajo el nombre de un parque de diversiones: Pantilandia.

Todos los ideales de orden adquieren un cariz ridículo en los discursos obsesivos, casi maniáticos, de Pantaleón Pantoja y en los elogios hiperbólicos que recibe de sus superiores. Mientras tanto, el poder indomable de la sexualidad se va abriendo paso en la existencia del capitán, desde el aumento en la frecuencia de sus pulsiones sexuales, hasta la ruptura de toda regla para poder saciar sus deseos con la Brasileña, y luego con otras visitadoras. Solo después de haberse dejado llevar por la compañía de las visitadoras, Pantaleón es capaz de expresar emociones, como la risa y el llanto, y se muestra, por primera vez en toda la historia, relajado, humano. Su transformación lo lleva a rendir homenaje militar al cuerpo de la Brasileña, caído en el desempeño del deber y así exigir un imposible: el desenmascaramiento de una sociedad hipócrita que denosta la prostitución al mismo tiempo que se sirve de ella.

Es la Brasileńa, paradigma de mujer fatal que "se ha pasado la vida haciendo estragos" (116), quien termina por adquirir imperio sobre Pantoja, rompiendo todas las bases del orden que él representa. Primero se ríe abiertamente de los eufemismos con que Pantoja pretende civilizar los servicios sexuales (131). Luego lo incita a romper gradualmente sus propias reglas: obtiene pagos y condiciones preferentes, creando así relaciones laborales desiguales entre las prostitutas; toca, seduce y tiene relaciones sexuales con Pantoja, quien así le es infiel a su esposa. Al final él está dispuesto incluso a ignorar algunas órdenes de sus superiores. Si en algún momento el disciplinado servicio de visitadoras crecía y parecía convertirse en una realidad clandestina pero plenamente aceptada dentro del 
ejército, con la presencia de la Brasileña se exhibe la imposibilidad de someter la sexualidad desbordante al orden civilizado que, en su forma más caricaturesca, representaba Pantoja.

A través de la Brasileńa y el cuerpo de visitadoras, la novela de Vargas Llosa, en su universo carnavalesco, pone a dialogar dos polos opuestos que, al entrar en relaciones recíprocas, exhiben la hipocresía y la debilidad de las bases sobre las que se sustenta el orden y la civilización patriarcal.

En el tratamiento cinematográfico que Lombardi da a esta historia, se advierten transformaciones que afectan al abordaje retórico de la sexualidad poderosa. Se atenúa el concierto de voces que trastornan la identidad de Pantaleón, incluso desaparecen algunos personajes que amplificaban la imagen de Iquitos como un mundo carnavalesco, de modo que la trama se concentra en las dificultades que enfrenta Pantoja para poner en marcha el servicio de visitadoras; en este sentido, la identidad del personaje tiene un perfil más individualizado y sensible, y su relación con la mujer fatal adquiere las dimensiones de un romance ilícito y catastrófico. Adicionalmente, se rompe con la pauta de interpretación que inauguraba el epígrafe de Flaubert; mientras en el libro todos pasaron por encima de Pantaleón, en la película este adquiere un aliado importante: las prostitutas.

En la obra de Vargas Llosa, la madrota y los cafiches deseaban debilitar a Pantoja: "Qué bueno sería verlo caer por fin en las redes de una mujer: los enamorados siempre se ponen blandos. Él es demasiado recto, le hace falta" (Vargas Llosa, 2010: 116), asegura Chuchupe. En cambio, en la película ella guarda una enorme lealtad y admiración por Pantoja, e intenta evitar que entre en el servicio de visitadoras la mujer fatal conocida como la Colombiana: ${ }^{7}$

${ }^{7}$ Probablemente la sustitución del apodo "Brasileña" por el de "Colombiana" se deba a que se procuró adaptarlo a la nacionalidad de la actriz Angie Cepeda. 
"no se la recomiendo, esa mujer es sumamente difícil" (Lombardi, 1999: min. 48:15).

En la identificación del ejército con un burdel, el efecto central en la novela era de rebajamiento hacia la imagen del ejército; en la película, aunque no deja de producirse ese fenómeno, queda bastante matizado, a la par que se desarrolla una especie de redención civilizadora hacia el mundo de las prostitutas: porque intentó proteger a Pantoja de la Colombiana, reconoció los beneficios del servicio de visitadoras, se defendió valientemente de las agresiones externas, e intentó retener a Pantoja, para conformar un negocio independiente, una vez que fue suprimido el del ejército; quizás más importante: nunca menoscabó el sentido del orden ni las reglas de Pantoja, quien a su vez admitió que la prostitución "es una labor difícil y arriesgada" (2:03:29). El ejército se muestra injusto y desagradecido, en cambio, Pantoja forjó amistades, expresadas en toda su emotividad en la penúltima escena, donde madrota, cafiches y prostituta escuchan entre lágrimas la carta enviada por Pantoja desde la lejana y fría región a donde fue enviado como castigo por rendir homenaje militar a una visitadora.

En este sentido, la Colombiana es la saboteadora del servicio de visitadoras. Solo por ella y con ella Pantaleón viola las reglas; no es el mundo de Iquitos el que trastorna su identidad. La sexualidad poderosa de la Colombiana lo debilita, lo llena de culpa y cada vez lo absorbe más -en la película aumentan considerablemente las escenas en que Pantoja aparece en compañía de su amante-. En este contexto, la muerte de ella resulta una tranquilizadora vuelta al orden. Los principios civilizatorios patriarcales se mantienen casi intactos, capaces de imponer el orden deseado incluso en la prostitución; en cambio, la sexualidad poderosa, caótica, que resiste a las reglas, resulta un elemento dańino que parece preferible mantener al margen. No obstante, esta última se mantiene como un elemen- 
to latente, extremadamente deseable y seductor, que le recuerda al orden sus debilidades.

Sí hay un momento claro en que la Colombiana se constituye en medio de crítica a la represión sexual del orden imperante, y es cuando se pone la ropa de dormir de la esposa de Pantoja: “¿Así duermen las señoras decentes? [...] Parezco una monja” (1:50:24). La escena puede parecer un insulto a la esposa legítima, pero al mismo tiempo, en el contraste del cuerpo desnudo con una pieza que cubre el cuerpo hasta el cuello, denuncia la represión sexual del mundo de Pantoja.

\section{El despertar del súcubo en Luna caliente}

Ramiro, argentino de familia acomodada, regresa a su país en 1977 -el peor año en la dictadura de Rafael Videla- luego de realizar estudios de medicina en París. En una visita a unos amigos de la familia, en medio del calor, sus deseos irrefrenables y su personalidad sociópata lo conducen a violar a Araceli, ahorcarla hasta dejarla sin respiración, y luego matar al padre de esta. Sus actos desencadenan fuerzas que él no puede controlar: Araceli se levanta transformada en una especie de súcubo dispuesto a acosar y absorber hasta la última gota de energía de Ramiro; la policía, bajo la certeza de que él asesinó al padre de Araceli, se propone usar esa información para perseguirlo y obligarlo a alinearse al régimen dictatorial.

Ana García ha señalado que la sexualidad poderosa es el eje argumental de la novela de Mempo Giadinelli:

Inicialmente subordinada a la autoridad del padre, tras su pérdida, Araceli asume una posición de poder, rechazando los valores tradicionales y burlándose de la sociedad. [...] desde que el acto de violación la inicia en la participación activa de la sexualidad, 
Araceli asume la posición de superioridad vis-à-vis-Ramiro (García, 1993: 172-173).

Según la misma autora, esta sexualidad es la lente a través de la cual se promueve una lectura particular de la dictadura argentina:

El texto, pues, concluye resaltando la ambigüedad entre víctima y victimario que existe entre Araceli y Ramiro, lo que alude, indudablemente, a las atroces torturas y violaciones de innumerables mujeres argentinas por oficiales militares durante esa época de criminal intolerancia en el país. [...] La posición de poder de la judía Araceli ante el machismo institucionalizado que simbolizan Ramiro, Gamboa y Almirón (los oficiales de la policía) hace patente que la liberación femenina está cargada de ramificaciones políticas (175).

Se activa, pues, el sistema argumental de las relaciones recíprocas protagonizado por la mujer fatal para hacer una crítica a la dictadura y al sistema patriarcal. Antes de la violación, Araceli se limitó a mirar a Ramiro "con una insistencia que lo turbaba y que él imaginó insinuante" (Giardinelli, 2000: 6), pero sin emitir ni una sola palabra. En su aparente pasividad de jovencita de 13 años, Araceli sugiere un poder capaz de conducir a Ramiro a la fatalidad; solo era necesario que despertara al volcán dormido.

Todo esto se narra desde un discurso focalizado en Ramiro, que da cuenta de sus monólogos internos y así se muestra el conflicto de un personaje ególatra reticente a asumir la responsabilidad de sus actos, pero que termina por hallar fisuras en su propia identidad. La violación, en vez de reafirmar al varón, libera la avasalladora sexualidad de la mujer, que conduce al hombre a reconocer su debilidad: "Odiaba a las mujeres, solo entonces se daba cuenta" (28), "Por desearlas y necesitarlas, les tenemos miedo" (29). Surge así 
una reflexión sobre su propio machismo, ligado a su origen sociocultural, que lo llevó a violentar a una púber de provincia porque se sabía impotente ante las mujeres adultas del mundo civilizado parisiense: "el argentino maula que no fue capaz de alzarse a una francesita en París, anoche se había convertido en un vulgar violador"; "cada mujer que había conocido en su vida había significado un minuto de terror [...] Quizá eso era el machismo, ese segundo de espanto que nos produce reconocer su sensatez, su aparente fragilidad (lo que nosotros queremos ver como fragilidad)" (29).

Los actos que rodean y suceden a la violación, lo obligan a reconocerse como "Frío, inescrupuloso" (21), no muy distinto a los policías de la dictadura, y de los cuales, paradójicamente, se salva gracias a la intervención de Araceli, la mujer que lo había llevado "a la condición de marioneta" (62). Sin embargo, su ego resiste a claudicar. En varias ocasiones procura justificarse a sí mismo y salvarse de asumir la responsabilidad de sus actos, pero el súcubo lo perseguirá aun después de una segunda muerte y más allá de las fronteras de Argentina.

La participación de la dictadura hace que la novela pueda ser leída como una reivindicación del poder y la libertad que representa la mujer, pero también como una crítica a la forma en que esta es reducida por el sistema patriarcal: en Luna caliente el hombre es debilitado y perseguido por dos tipos de dictadura, la política y la sexual -la segunda más poderosa que la primera-, sin embargo, no es realmente una víctima, porque, en la brutal violación de Araceli y en la frialdad con la que mató al padre, los padecimientos de Ramiro son la consecuencia de los monstruos que él mismo ha creado. Todo esto debido a que la voz de Araceli solo se hace escuchar después de la violación, y es una voz casi animal que expresa claro y fuerte sus deseos, pero no enuncia ideas complejas: "No me hiciste daño. Me gustó. Y quiero hacerlo de nuevo; quiero que vengas esta noche" (Giardinelli, 2000: 32); "No tengo nada que hablar de eso. 
No quiero hablar [...] No quiero porque no quiero" (61); "Quiero - dijo ella con voz de niñita perdida en un aeropuerto-. Lo quiero ahora” (62). Así, Araceli resulta la consecuencia de un sistema violento, creado por los propios hombres, quienes devienen en víctimas de su propia creación. Antes de la violación, la mirada de Araceli tenía distintas posibilidades de significación y desarrollo; luego se reducen a una sola: una nueva forma de sometimiento.

Esta ambigüedad de las relaciones entre víctima y victimario asociadas al machismo, tan importantes en la novela, no desaparecen, pero se diluyen en la película de Roberto Denis. En esta, la narrativa de focalización externa corre siempre a cargo de la cámara, el espectador no tiene acceso a la conciencia de Ramiro y no percibe un conflicto interno que denuncie abiertamente al machismo. En la actuación de Humberto Zurita, Ramiro mantiene un gesto impenetrable y duro que solo se quiebra luego de que sus crímenes lo conducen a las lágrimas, o cuando sonríe tiernamente a su hermana.

En la película, la dictadura y el ambiente de represión se convierten en los ejes temáticos que lo impregnan todo, y resaltan desde las primeras escenas, donde los padres de Araceli hablan insistente y dolorosamente de un hijo valiente desaparecido por la dictadura; le advierten a Ramiro que el gobierno le ha dado facilidades para obtener una plaza laboral porque se espera en él a un aliado, un "cómplice". Por su parte, Araceli no expresa mayor interés en ninguno de estos temas, más bien se concentra en Ramiro, mostrando desde un inicio la frialdad de la mujer fatal.

Dentro del ambiente agobiante y caluroso, Araceli no es una púber callada, sino una joven de más edad, abiertamente provocadora e incitante; hace preguntas insistentes y curiosas, roza a hurtadillas los pies de Ramiro con los suyos, lo mira desde el balcón tocándose el nacimiento de los senos. Con ese papel activo, la película sugiere que, si no la provocó, al menos Araceli no es del 
todo inocente en la violación posterior. De esta forma, las ocasiones siguientes en que Araceli persigue a Ramiro y lo acorrala no parecen sino parte de una escalada de acoso en donde Ramiro es el menos responsable. No obstante, se favorece una lectura política en la medida en que el papel activo de Araceli en la seducción de Ramiro se alterna con la presencia fantasmagórica del hermano rebelde. Araceli y su familia adquieren así un papel relevante como opositores al régimen.

En esta escalada, el asesinato del padre de Araceli aparece como un accidente, con ciertos rasgos de defensa propia en medio de la actitud abiertamente hostil que manifestó don Braulio contra Ramiro. La culpa de este se atenúa también porque muestra arrepentimiento: llora y abraza el cadáver, asegurando que la culpa fue del muerto: “¿Qué me hiciste?, borracho, viejo de mierda, ¿qué me hiciste?” (Denis, 1985: 31:51). Ahí pareciera una víctima, un hombre que no se supo controlar, y no un sociópata que merece ser perseguido por la policía y por Araceli.

Para reafirmar la imagen de víctima de Ramiro, en el medio de una confrontación política, se le muestra como procedente de una familia unida de valores convencionales. La hermana cobra un papel mucho más relevante que en la novela -donde apenas recibe unas cuantas menciones-, lo abraza, le hace saber lo difícil que fue crecer sin él, le advierte: "No vayas [...] Ella no es para vos. Es una putita de pueblo y te está volviendo loco" (01:11:00). También lo alerta contra la policía "No les creas, ellos prometen, engañan" (1:12:48). En el esfuerzo de crear la imagen de una familia de mujeres que tratan de proteger al hombre de su casa, la hermana proporciona a Ramiro los medios para que huya de la policía y de Araceli, a quien juzga y desprecia como una mujer fatal, reafirmando así los valores patriarcales.

En contraste con esta imagen de familia unida y protectora, hay una escena en que Araceli es exhibida como un ser insensible 
y ajeno a cualquier valor familiar: "Araceli, yo maté a tu viejo, ¿me entendés? ¡Maté a tu viejo!, ¿me entendés? Y fue por vos, porque me volvés loco, me convertís en un animal, en un asesino" (01:21:09). ${ }^{8}$ Como única respuesta, Araceli intenta besarlo, se niega a hablar y, ante la resistencia de Ramiro, reclama “¡Mierda!, son un miedoso, un maricón”. Mientras él expresa remordimientos, ella parece la sociópata. En el juego de las relaciones recíprocas, el poder sexual que debilita al hombre aparece como una amenaza a cualquier valor social, familiar y civilizatorio, y a esta dictadura del sexo femenino se suma la política, para hacer aún más opresivo el ambiente.

Aunque los fundamentos del sistema patriarcal y machista no son puestos en tela de juicio, ella simboliza, por su origen familiar y su papel activo, la oposición a la dictadura. Ella se hace cómplice de Ramiro, lo ayuda a ocultar su culpabilidad en el crimen, y en este tránsito se enfrenta a la oficialidad. Ella, igual que su padre y su hermano, es una disidente; su presencia poderosa y desafiante se opone al sistema político. Al llamarlo "maricón”, también está sugiriendo la cobardía y pasividad política del sector aburguesado que Ramiro y su familia representan.

\section{Lulú quiere ser mujer fatal}

En las primeras páginas de Las edades de lulú, el lector se adentra en la conciencia y las fantasías sádicas de una mujer que disfruta de la pornografía homosexual y anhela someter e incluso infringir dolor a los hombres de la pantalla. La transgresión hacia las con-

${ }^{8}$ En la novela, la intervención de Ramiro resulta francamente tímida, quiere hablar "de todo lo que pasó" (Giardinelli, 2000: 61) pero jamás especifica de qué ni mucho menos reconoce abiertamente su asesinato. Araceli no es confrontada con la verdad, aunque todo apunte a que la conoce, de modo que puede evadirla. 
venciones que atraviesa toda la novela comienza con una mujer ajena al estereotipo cultural de la dama frágil y recatada, pues expresa abiertamente deseos sexuales no convencionales, incluso sádicos, y ve películas pornográficas cuyo disfrute la sociedad tiende a atribuir de forma exclusiva a los varones; esas películas, además, exhiben conductas sexuales censuradas por el régimen franquista; Lulú es divorciada, independiente y amoral, lo más cercano a una femme fatale.

A estas primeras escenas suceden las de una niña que desde los quince ańos aceptaba y disfrutaba abiertamente de su sexualidad, transgrediendo las convenciones morales y patriarcales de su entorno, así lo admiten ella misma - "Me reconocí a mí misma deshonrada, era delicioso" (Grandes, 2008: 55)-, Pablo - "Siempre he sabido que eras una niña sucia, Lulú” (55)-, y su amiga Chelo - ¡¡[...Lulú] tú eres como un tío!, solo vas a lo tuyo y, hala, sin pensar en nada más" (88)-. Se trata, pues, del relato de una Lolita que se convertirá en mujer mayor y cuya existencia se deslizará entre, y subvertirá siempre, las fronteras: niña-mujer, mujer-hombre, dominante-dominada, amante-esposa, hermana-amante, víctimavictimaria.

Con Pablo, el mejor amigo de su hermano mayor Marcelo y a quien conoció desde que era una niña, se inaugura una sorda lucha de poderes. La rebeldía transgresora y la excitante ilusión de tener el control de las situaciones sexuales y amorosas en las que se involucra conviven con los deseos de -o la incapacidad de resistirse aser controlada y dominada por el macho. Este, aunque la incita a explorar cosas nuevas y es cómplice en las fantasías sádicas de Lulú -que los llevan a conocer al travesti Ely-, siempre tiende a ejercer cierto control sobre ella, y ella acepta ser infantilizada por y para él, incluso después de haberse convertido en madre y profesionista. En esta lucha, en la que Pablo resulta casi siempre triunfante, los deseos sádicos de Lulú se revelan como expresión de una naturale- 
za dual y de un yugo invisible del que no se puede zafar: "Sentí que nunca llegaría a ser una mujer fatal, una mujer como Dios manda. Mi estrategia se había vuelto contra mí” (178).

Así, cuando se divorcia de Pablo, inicia una búsqueda independiente de placeres que también se vuelve en su contra: paga a homosexuales para verlos, e incluso participar, mientras tienen relaciones sexuales, pero se vuelve tan adicta a esas actividades que no le alcanza el dinero y termina por prostituirse en circunstancias clandestinas que amenazan con quitarle algo más que la dignidad. Es ahí cuando la dominación, de la que nunca logra escapar del todo, se revela en toda su magnitud, en un Pablo que la salva pero que al mismo tiempo parece haber orquestado todo para que Lulú volviera a él:

Luchaba contra aquella certeza disfrazada de sospecha y no encontraba alternativa alguna, no existían alternativas, él había estado allí, moviendo los hilos a distancia, podía imaginármelo, podía ver su cara, los ojos brillantes, los labios apretados, podía escuchar sus palabras exactas, ¿quieres peligro?, toma peligro, lo habría dicho en voz baja, sin gritar, sin alterarse, le conocía demasiado bien, podía verle, escucharle, pero aquello era demasiado duro, de una dureza insoportable para las fuerzas de una niña pequeña, concluí [...] (277-278).

En su intento por alejarse del dominio que la mantiene en una burbuja de niña -atrevida, sexual y desafiante, pero nińa a fin de cuentas-, Lulú se sumerge en experiencias cada vez más destructivas. Incapaz de tener total control de su propia vida, y a pesar de las sospechas de que Pablo le tendió una trampa, termina satisfecha de poder volver a sentirse segura en los reconfortantes brazos de un esposo-padre. 
Relatadas en primera persona, Las edades de Lulú son las etapas por las que atraviesa una mujer cuya sexualidad poderosa rompe con distintos modelos sociales y culturales hegemónicos. Así lo advierte Ana Corbalán:

novela que critica los modelos de género impuestos al defender la pluralidad sexual y las contradicciones que caracterizan a la mujer del siglo xx. Por otro lado, por medio de la apropiación del género erótico, Grandes ha logrado destruir los códigos represivos al establecer una llamada a la diversidad y pluralidad sexual, transgrediendo las ansiedades morales que giran en torno al tema del sexo (Corbalán, 2006: 76).

Sin embargo, Lulú no rompe el molde más importante, el de la dominación patriarcal; la fatalidad termina arrastrándola y debilitándola a ella en lugar de al varón que en algunos momentos creía dominar. La fallida aspiración a convertirse en femme fatale puede leerse entonces como el deseo de independizarse y liberarse de la autoridad patriarcal. El tema-personaje es objeto de apropiación por parte de la escritura femenina, y adquiere una connotación abiertamente positiva en el marco de la liberación sexual y de la mujer posterior al régimen franquista.

A partir de esta lectura de la novela, no deja de resultar irónica la interpretación del personaje en la película de Bigas Luna. La narrativa aquí es lineal, con focalización externa predominante salvo algunos momentos en que se hace presente la conciencia de Lulú por medio de la voz en off-, y ofrece el crecimiento, desde bebé, de una mujer inocente, pero al mismo tiempo sexualmente muy despierta, que pasa por la iniciación sexual, el matrimonio, el divorcio y la vuelta necesaria al matrimonio. Esta versión de Lulú carece casi por completo del componente sádico, de modo que resulta mucho más inocente, infantil y frágil; llora en varios 
momentos de indefensión en que no quiere hacer lo que demanda Pablo, y él, aunque no deja de ser autoritario, con cierta frecuencia responde con consuelos y peticiones de perdón.

El Pablo novelesco, ajeno a todo romanticismo, es tajante, dominante e incluso violento -cuando ella se resiste a lo que él quiere, amenaza con irse o llevarla a casa, y llega al extremo de violarla-, pero en el juego de dominación sí llega a balbucear, a quedarse boquiabierto y sin palabras ante Lulú (Grandes, 2008: 165). En cambio, el de Bigas Luna es casi un romántico; escribe cartas amorosas, carga a su mujer para entrar a su nueva casa el día de su matrimonio, la consuela cuando ella reconoce que es muy mala cocinera, se muestra condescendiente con Ely cuando Lulú es muy egoísta e insensible con ella. Él nunca pierde su fortaleza ni su rol dominante ante Lulú, porque ellos no juegan un juego de poder más allá de los límites del jugueteo sexual, e incluso ahí, Pablo siempre tiene la última palabra.

En la adaptación fílmica, Lulú es insegura, experimenta sexualmente por celos: "si no me hubiera prestado al juego, te habrías ido a la cama con Cristina” (Bigas Luna, 1990: 01:03:19). Ella no reafirma su naturaleza sexual como algo que disfruta y es parte de su identidad, sino que resulta una "válvula de escape" (01:07:56), "era la salida. Era para mí como la comida para alguien que quiere calmar sus nervios. Con el sexo por lo menos no engordaría" (1:17:20-30). Como se ve, en ocasiones Lulú incluso cae en expresiones que suenan a cliché, especialmente al final, cuando después de haber experimentado la vida sin límites, reconoce que su vida con Pablo era lo mejor: "Siempre he sido feliz" (01:37:21).

Los elementos transgresores de la novela se debilitan considerablemente en la película. Las escenas con homosexuales se difuminan y tienden a tener como centro una relación heterosexual, el sadomasoquismo se diluye en juegos inocentes con cuero y estoperoles. El Pablo fílmico no participa en la planificación de la escena 
en que Lulú está a punto de ser violentada, se entera por informes de Ely la misma noche de los acontecimientos, y el rescate de Lulú tiene como consecuencia la muerte trágica del transexual, con lo que la rebeldía de la mujer contra el marido resulta catastrófica para terceras e inocentes personas.

Así, en la narración cinematográfica los elementos transgresores al statu quo casi desaparecen, porque las relaciones recíprocas se tornan unidireccionales y convencionales, porque Lulú nunca tiene el poder y su sexualidad se interpreta como una forma en que la mujer burguesa evade el tedio de una vida despreocupada. La femme fatale se reduce a un inventario de clichés: la Lolita que seduce al hombre mayor, la mujer que tiene relaciones y deseos sexuales no convencionales. La mayor transgresión de este personaje fílmico consiste en exhibir y aceptar abiertamente su sexualidad y participar voluntariamente en actos que transgreden la moral sexual burguesa, y que serán exhibidos en el cine ante un público confrontado con sus propios deseos.

\section{Consideraciones finales}

En el estudio de tres mujeres fatales del cine y la literatura se han mostrado distintas posibilidades de significación del tópico de la sexualidad poderosa. Al sentido tradicional de la mujer como perdición del hombre se superponen otros que apuntan a cuestionar e incluso subvertir los valores del statu quo, ya sea el orden militar, el sistema dictatorial o la moral y la sexualidad convencionales, todos ellos procedentes de un sistema patriarcal que presupone el dominio y la superioridad del varón sobre la mujer. La mujer fatal, al erigirse en un ser más poderoso que el varón, totalmente deseable, y con motivos más o menos válidos para transgredir el orden masculino, deviene en algo más que un ser condenable; su subversión resulta necesaria en tanto que evidencia las debilidades, 
hipocresías y autoritarismos de un sistema decadente que se sustenta en la negación o el control de la sexualidad.

Las prostitutas en la obra de Vargas Llosa, al aceptar abiertamente su sexualidad y ser congruentes consigo mismas, se muestran auténticas y poderosas frente a varones incapaces de controlar sus propios instintos, pero al mismo tiempo obsesionados por racionalizar, ordenar y civilizar. La poderosa sexualidad de Araceli en la novela de Giardinelli permite que la joven se distancie del rol de víctima de una violación y se torne en fuerza capaz de carear al varón con su propio machismo, con sus debilidades e inseguridades. La descarada Lulú confronta los prejuicios del lector con una mujer liberal y deseante, con deseos nada convencionales, a la par que expresa la lucha de la mujer por tener control sobre su destino; también, exhibe las relaciones de poder que sostienen los sexos, relaciones desiguales porque a fin de cuentas él tiene más experiencia en el ejercicio de la libertad, el poder y el control, mientras la mujer tiene la desventaja de la inexperiencia. Estas relaciones están en constante riesgo de crisis ante el empuje de Lulú .

Sin embargo, es claro que no todos los relatos que involucran mujeres fatales resultan igualmente rupturistas. En especial, las adaptaciones cinematográficas acusan deslizamientos narrativos y temáticos que conllevan una tendencia a difuminar las puertas transgresoras que pudo abrir la mujer fatal; en este sentido, el mayor señalamiento que hacen las películas es hacia la doble moral, la pasividad política y la represión de la sexualidad por parte de la sociedad burguesa.

La película de Lombardi reivindica a las prostitutas que han sido históricamente estigmatizadas, pero a costa de someterlas al orden civilizatorio masculino que sólo se ve cuestionado en su puritanismo; la que no se ajusta se mantiene como una amenaza latente, bella, absolutamente deseable, que insinúa las contradicciones e hipocresías de ese orden, pero amenaza al fin. La de Denis, al eli- 
minar los conflictos internos del macho y fortalecer el rol víctima, refuerza la asimetría de las relaciones entre Ramiro y Araceli y, por tanto, la amenaza que representa la mujer poderosa para el varón; Araceli queda rodeada de clichés culturales que tienden a culpar a la mujer de la violación, atenuando la responsabilidad del varón, y así se diluye el acto justiciero que supone el empoderamiento de Araceli. En Bigas Luna, la asimetría en las relaciones de pareja donde domina el varón no supone mayor conflicto, se reafirma el rol paternal del varón al mismo tiempo que se infantiliza a la mujer, una más estereotipada, que explora menos por voluntad y deseos propios y más por incitación del varón, o por celos.

La exploración a través de algunas novelas y películas a lo largo de este artículo deja claro lo necesario que es comprender en su complejidad al personaje de la mujer fatal, la importancia de estudiar su función retórica en cada discurso. Sobre todo, porque es un personaje que conduce a problematizar la propia cultura.

También quedan preguntas abiertas. Es innegable que hay literatura que estigmatiza sin tapujos a la mujer fatal, pero sin duda hay novelas que se apoyan en ella para cuestionar el orden establecido. En cambio, lo que ocurre en la adaptación cinematográfica en el corpus aquí analizado es inquietante: ¡acaso todas las adaptaciones resultan más conservadoras que las novelas en cuanto a la representación de la mujer fatal? ¿Hasta qué punto el cine, un tipo de discurso susceptible de difusión masiva, se ha atrevido a construir mujeres fatales que desafían el statu quo? 


\section{Bibliografía}

Aristóteles, 1990, Retórica, Quintín Racionero (trad.), Gredos, Madrid.

Bigas Luna, José Juan (dir.), 1990, Las edades de Lulú, Iberoamericana Films, España.

Booth, Wayne C., 1974, Retórica de la ficción, Santiago Gubern Garriga-Nogués (trad.), Antoni Bosh, Barcelona.

Bornay, Erika, 2008, Las hijas de Lilith, Cátedra, Madrid.

Cabello Pino, Manuel, 2010, Motivos y tópicos amatorios clásicos en El amor en los tiempos del cólera, Universidad de Huelva, Huelva.

Cánovas, Rodrigo, 2003, "Pantaleón y las visitadoras", en Sexualidad y cultura en la novela hispanoamericana: La alegoría del prostibulo, LOM, Santiago de Chile, pp. 41-51.

Corbalán, Ana, 2006, "Contradicciones inherentes a 'Las edades de Lulú: Entre la transgresión y la represión", Letras Femeninas, vol. 32, núm. 2, pp. 57-80.

Curtius, Ernst Robert, 1995, Literatura europea y Edad Media lati$n a$, t. 1Margit Frenk Alatorre y Antonio Alatorre (trad.), Fondo de Cultura Económica, Madrid.

Denis, Roberto (dir.), 1985, Luna caliente, Frank Producciones, Argentina.

Eetessam Párraga, Golrokh, 2016, "Lilith y sus descendientes: trayectoria del mito de la 'femme fatale' en las literaturas europeas", Tesis doctoral, Universidad Complutense de Madrid, Madrid.

Esteban Hernández, María Luisa, s.f., "Mario Vargas Llosa, su obra en el cine", Biblioteca Complutense. Disponible en: http:// webs.ucm.es/BUCM/fll/47039.php. 
Flaubert, Gustavo, 1891, La educación sentimental, Giner de los Ríos (trad.), Imprenta de Tomás Minuesa, Madrid.

García Berrio, Antonio, 1984, "Retórica como ciencia de la expresividad. (Presupuestos para una retórica general)", Estudios de Lingüistica, núm. 2, pp. 7-59.

García Chichester, Ana, 1993, "Jerarquía de los géneros sexuales en Luna caliente de Mempo Giardinelli", Romance Notes, vol. 34, núm. 2, pp. 169-176.

Giardinelli, Mempo, 2000, Luna caliente, Seix Barral, Buenos Aires. Disponible en: https://currikicdn.s3-us-west-2.amazonaws. com/resourcedocs/590f75b38fd5a.pdf

Grandes, Almudena, 2008, Las edades de Lulú, Tusquets, México.

Lombardi, Francisco (dir.), 1999, Pantaleón y las visitadoras, América Producciones / Inca Films, Lima.

López Martínez, María Isabel, 2008, El tópico literario. Teoría y critica, Arco/Libros, Madrid.

Márquez, Miguel Ángel, 2002, “Tema, motivo y tópico. Una propuesta terminológica”, Exemplaria, núm. 6, pp. 251-256.

Meléndez Martin, Javier, 2018, "La 'femme fatale': al cine le salió el tiro por la culata al parodiar a la mujer que no quería ser esposa ni madre", Yorokobu, 12 de septiembre. Disponible en: https://www.yorokobu.es/femme-fatale/

Moreno Fernández, Tomás, 2015, De Pandora a la femme fatale. Mitos figuras y estereotipos de estigmatización femenina, Dauro, Madrid.

Pérez Parejo, Ramón, 2004, "Modelos de mundo y tópicos literarios: la construcción ficcional al servicio del poder", Rlit, vol. 66, núm. 131, pp. 49-76.

Pimentel, Luz Aurora, 1993, “Tematología y transtextualidad”, Nueva Revista de Filología Hispánica, vol. 51, núm. 1, El Colegio de México, pp. 215-229. 
Quintiliano, Marco Fabio, 2004, Instituciones Oratorias, Ignacio Rodríguez y Pedro Sandier (trad.), Biblioteca Virtual Miguel de Cervantes. Disponible en: http://www.cervantesvirtual.com/ obra/instituciones-oratorias--0/.

Sanabria, Carolina, 2018, "Modelos de la femme fatale en el cine de Bigas Luna: Lola y Lulú”, Espiga, núms. 16 y 17, pp. 41-57.

Vargas Llosa, Mario, 2010, Pantaleón y las visitadoras, Alfaguara, México. 